12th LUMEN International Scientific Conference Rethinking Social Action. Core Values in Practice | RSACVP 2019 | 15-17 May 2019 | lasi - Romania

\title{
Evolution of Scientific Research in Higher Education of Physical Education and Sport in the Republic of Moldova through Doctoral Studies
}

\author{
Liliana BUDEVICI - PUIU, Mihail ONOI, \\ Anatolie BUDEVICI - PUIU
}

https://doi.org/10.18662/lumproc. 151

How to cite: Budevici - Puiu, L., Onoi, M., \& Budevici - Puiu, A. (2019). Evolution of Scientific Research in Higher Education of Physical Education and Sport in the Republic of Moldova through Doctoral Studies. In C. Ignatescu (ed.), 12th LUMEN International Scientific Conference Rethinking Social Action. Core Values in Practice, 15-17 May 2019, Iasi - Romania (pp. 40-48). Iasi, Romania: LUMEN Proceedings. https://doi.org/10.18662/lumproc.151 


\title{
Evolution of Scientific Research in Higher Education of Physical Education and Sport in the Republic of Moldova through Doctoral Studies
}

\author{
Liliana BUDEVICI - PUIU1, Mihail ONOI ${ }^{2}$, \\ Anatolie BUDEVICI - PUIU 3
}

\author{
Abstract
}

The modernization of the higher education in the Republic of Moldova with a view to its integration into the Common European Area of Higher Education, its improvement at international level, the recognition of periods and study papers are important factors that have generated the development of higher education PhD studies in the physical education and sport, kinetotherapy and recreation. In Moldova the efficient organization and conduct of the research-development-innovation activity has become a key factor of progress. The importance and necessity of scientific research is reflected by the complexity of the economic activities of national economic agents which are under the strong influence of the international market and of the imperatives generated by the position of science as the main production force. Also, at national level and at the bigher education institution of physical education and sport level, the strategy for the development of scientific research aims at maintaining dynamic and competitive knowledge-based studies capable of providing sustainable and lasting growth. In this context, the bigher doctoral studies, the scientific results obtained at their completion and making the most of the scientific progress, have become an organic, dynamic and vital vocation for the unique higher education institution, unique from the Republic of Moldova.

Keywords: higher doctoral studies, PhD students, PhD supervisors, performance indicators, PhD theses.

\footnotetext{
${ }^{1} \mathrm{PhD}$, associate professor, The State University of Physical Education and Sports, Chisinau, Republic of Moldova, lilianapuiu27@gmail.com, +37368114146

2 Associate professor, The State University of Physical Education and Sports, Chisinau, Republic of Moldova, turspor@gmail.com, +37369516893.

${ }^{3} \mathrm{PhD}$, associate professor, The State University of Physical Education and Sports, Chisinau, Republic of Moldova, lilianapuiu27@gmail.com, +37368114145
} 


\section{Introduction}

The scientific research is part of the mission of the State University of Physical Education and Sport (SUPES), constituting the complementarity required for the learning process. A learning process based on generating new knowledge is more valuable and more competitive than a learning process that is reduced to a simple transfer of knowledge from teachers to students.

The scientific research strategy of SUPES is in line with the National Strategy for Research, Development and Innovation for the period 2014-2020, with development plan and policies of the European Research Area (ERA), and in agreement with the Framework Program Research and Innovation 2014-2020 (Horizont 2020) [2].

Also, one of the priority objectives of the university in the field is the development of a research focused on knowledge and innovation to boost competitiveness and growth. To achieve this objective, emphasis is placed on promoting research and development activities and facilitating innovation, by spread of TIC technologies and the sustainable use of resources. In this context, doctoral and postdoctoral studies ensure the efficient achievement of a significant part from the scientific performance of the higher education institution in the field of physical culture. The research activity and higher doctoral studies / postdoctoral studies, deepened in its area of competence, are conducted within the Doctoral School authorized to operate provisionally until its accreditation in 2020.

The mission of the SUPES Doctoral School is mainly focused on the training of high-performance specialists in the field of physical culture by offering creative study programs that integrate the results of scientific research and contribute to the intellectual development of students, master students and $\mathrm{PhD}$ students [1], [3], [4].

\section{Problem Statement}

The aim of the study is to analyze the evolution of scientific researches through doctoral studies in the higher education of physical education and sports in the Republic of Moldova.

\section{Research Questions/Aims of the research}

The main research directions of the university are in consonance with the scientific profile - professional pedagogy and scientific specialty - 
533.04 physical education, sport, kinetotherapy and recreation established on the basis of the Nomenclature of Scientific Specialties of the Republic of Moldova approved by Government Decision No.199 of March 13, 2013. They are as follows:

- Physical education in the education system. Professional training of teachers;

- Sports Medicine, Kinetotherapy and Recreational Physical Culture;

- Philosophical, socioeconomic, legal and managerial aspects of physical culture;

- Innovative technologies and scientific-methodological bases of the contemporary training system of the athletes.

Figure 1 schematically reflects the diagram of sustained theses and scientific titles (PhD in pedagogy) obtained by highly qualified teachers at the completion of doctoral studies within SUPES in the period 1996 and 2018. From the graphical representation we can see that during this period a number of 192 were sustained within the SUPES Scientific Council assigned according to the research directions as follows: Innovation technologies and the scientific-methodological bases of the contemporary training system of athletes - a number of theses of 85; Physical education in the education system. Professional training of teachers - 84 theses and scientific titles obtained; Philosophical, socioeconomic, legal and managerial aspects of physical culture - 13 theses; Sports Medicine, Kinetotherapy and Recreational Physical Culture - 10 theses.

The number of $\mathrm{PhD}$ students according to the nationalities, who sustained the doctoral theses in pedagogy in the period 1996-2018, within the State University of Physical Education and Sport is reflected in Figure 2. 


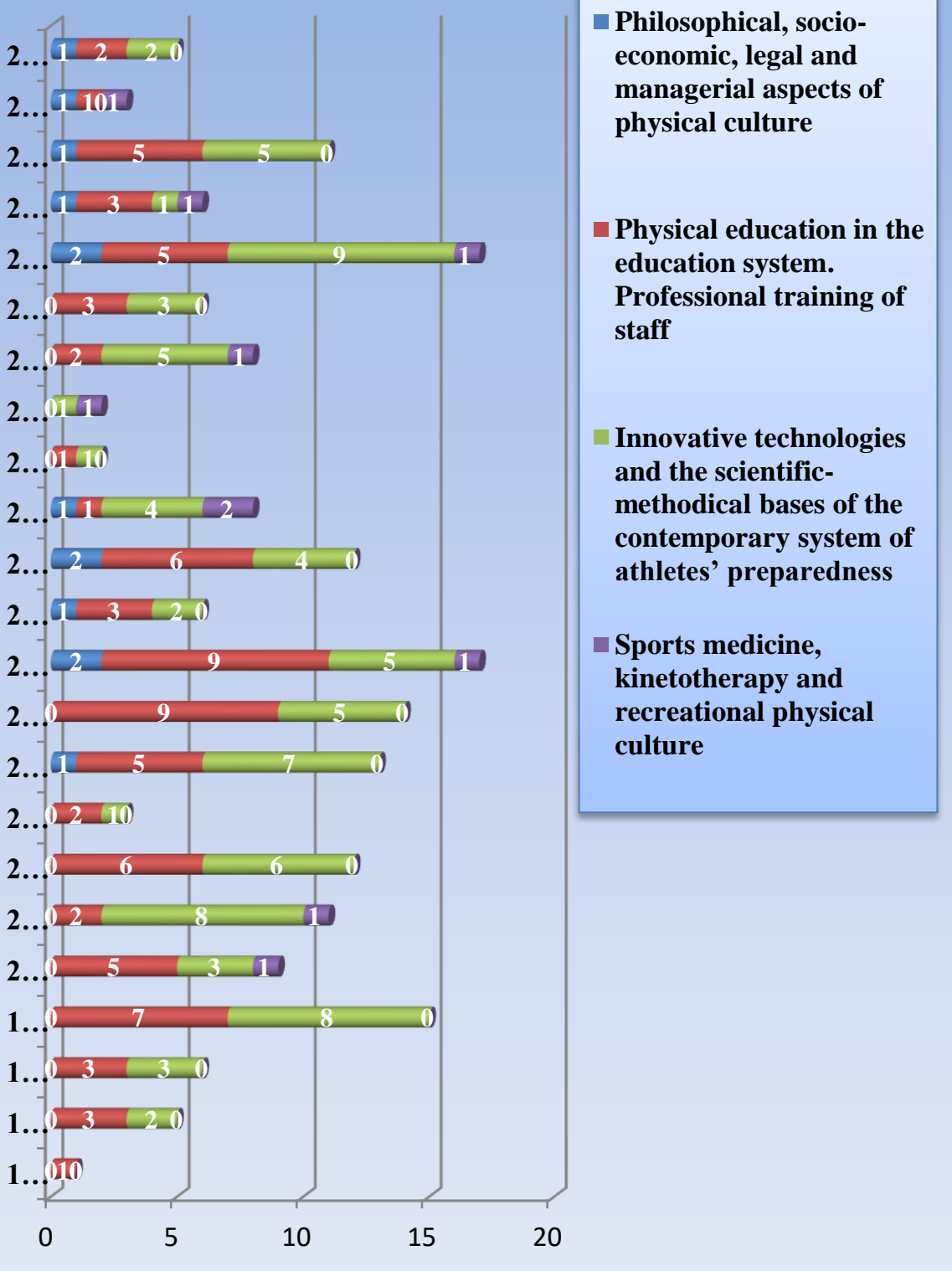

Figure 1. The number of $\mathrm{PhD}$ theses sustained within the SUPES during the years 1996-2018 according to the research directions 


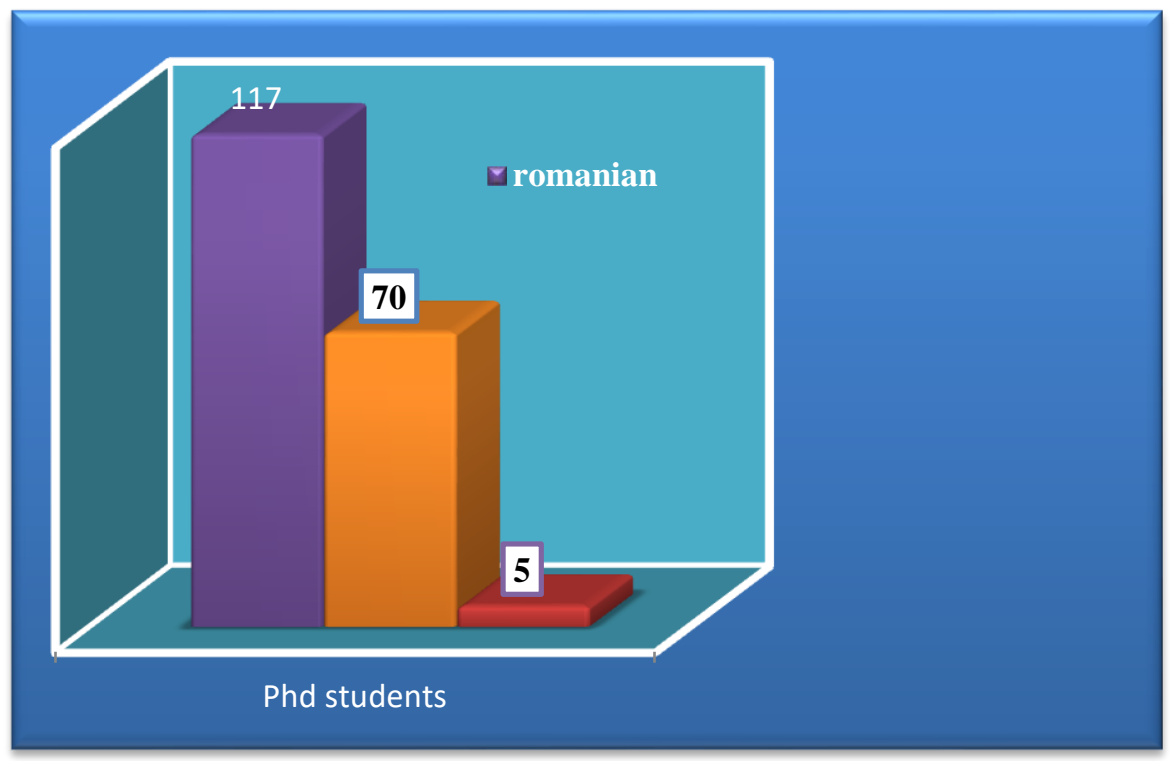

Figure 2. The total number of $\mathrm{PhD}$ students according to the nationalities, who sustained the doctoral theses in pedagogy in the period 1996-2018, within the SUPES

\section{Research Methods}

Methodology of research: analysis of scientific-methodical literature, pedagogical observation, the statistical and mathematical method of processing and interpreting data.

\section{Findings}

Doctoral School of SUPES consists of $35 \mathrm{PhD}$ students $(25-$ Republic of Moldova, employees of SUPES and 10 from Romania), 13 teachers, who ensure the development of the instructive process within the advanced training program of PhD students. During the years 2016-2018, 7 new $\mathrm{PhD}$ supervisors were admitted within the Doctoral School, and 10 members regained the right of $\mathrm{PhD}$ supervisor. Under the guidance of $\mathrm{PhD}$ supervisors, $86 \mathrm{PhD}$ students are trained (Table 1). 
Table 1. The contingent of $\mathrm{PhD}$ students in 2019

\begin{tabular}{|c|c|c|c|}
\hline \multirow{2}{*}{$\begin{array}{c}\text { PhD } \\
\text { students }\end{array}$} & $\begin{array}{c}\text { Republic of } \\
\text { Moldova }\end{array}$ & Romania & Total \\
\hline TOTAL & 35 & 51 & 86 \\
\hline
\end{tabular}

In Table 2 we present the results of admission to higher doctoral studies for the period $2016-2019$.

Table 2. The results of the admission to higher doctoral studies

\begin{tabular}{|c|c|c|c|c|c|c|c|c|c|c|}
\hline \multirow{3}{*}{ No. } & \multirow{3}{*}{$\begin{array}{l}\text { Year of } \\
\text { study }\end{array}$} & \multirow{3}{*}{$\begin{array}{l}\text { Form of } \\
\text { studies }\end{array}$} & \multirow{3}{*}{$\begin{array}{l}\text { Submit- } \\
\text { tted } \\
\text { appli- } \\
\text { cations }\end{array}$} & \multicolumn{6}{|c|}{ Admission } & \multirow{3}{*}{$\begin{array}{c}\text { Total } \\
\text { Admission }\end{array}$} \\
\hline & & & & \multicolumn{2}{|c|}{$\begin{array}{c}\text { Republic of } \\
\text { Moldova }\end{array}$} & \multicolumn{2}{|c|}{ Romania } & \multicolumn{2}{|c|}{ Other states } & \\
\hline & & & & budget & contract & budget & contract & budget & contract & \\
\hline \multirow[b]{2}{*}{1.} & \multirow{2}{*}{$\begin{array}{l}2016 / \\
2017\end{array}$} & daily basis & \multirow[b]{2}{*}{21} & 1 & - & \begin{tabular}{|l|}
- \\
\end{tabular} & - & \begin{tabular}{|l|}
- \\
\end{tabular} & - & 1 \\
\hline & & $\begin{array}{c}\text { low } \\
\text { frequency }\end{array}$ & & 3 & 8 & - & 8 & - & - & 19 \\
\hline \multirow[b]{2}{*}{2.} & \multirow[b]{2}{*}{$\begin{array}{c}2017 / \\
2018\end{array}$} & daily basis & \multirow[b]{2}{*}{30} & 1 & 1 & - & - & - & - & 2 \\
\hline & & $\begin{array}{c}\text { low } \\
\text { frequency }\end{array}$ & & 2 & 6 & - & 19 & - & - & 27 \\
\hline \multirow[t]{2}{*}{3.} & \multirow[t]{2}{*}{$2018 / 2019$} & daily basis & \multirow[t]{2}{*}{32} & 1 & - & & & & & 1 \\
\hline & & $\begin{array}{c}\text { low } \\
\text { frequency }\end{array}$ & & - & 9 & - & 22 & - & - & 31 \\
\hline
\end{tabular}

The general objective of the scientific and innovation research activity within the SUPES is to modernize the related structures from the higher education institution, including the Doctoral School, so that an integrated scientific research system is created, which generate coherent, complementary, competitive and efficient capabilities and capacities of research. At the same time, it is important to produce, specifically, to the level of performance, knowledge, methodologies and innovation and practical - applicative support. The achievement of this objective imposes compliance with the observance of certain basic and specific principles such as: of continuity, unity, completeness, complementarity, diversity, value, accuracy, interdisciplinarity and multidisciplinarity, cooperation, scientific and problematization debate, constructive dialogue, synergy principle, accessibility, promotion of scientific and innovation management in didactic 
activity and research, and last but not least the principle of finality and innovation.

In this context, the Doctoral School for the period 2015-2020 has approved its own development strategy in order to achieve the general objective of the scientific and innovation research activity of SUPES, which allowed it to ensure:

- the realization of scientific research projects, themes and research activities, distributed by teams (PhD supervisors and $\mathrm{PhD}$ students, Scientific-Pedagogical staff, young researchers), especially for the major issues of physical education in the education system, the professional training of teachers, as well as the innovative technologies and scientificmethodological bases of the contemporary training system of athletes;

- drafting and publication of some significant papers, especially of analysis, concepts, theories and innovative elements that generates new knowledge bases;

- methodologies of scientific research specific to this field.

In the knowledge society also has an essential role in evaluating higher education in the field on the basis of evaluation criteria and standards in order to be authorized / accredited the study programs. Among the criteria for determining the quality of education in the Republic of Moldova we can mention:

- the knowledge quality, professional skills and professional motivation of graduates;

- the professional training quality and motivation of the teaching staff;

- the correlation of education with current, economic and social requirements of modern society;

- the university research quality;

- the economic efficiency of higher education;

- equity and equal opportunities for access to higher education;

- the higher education infrastructure quality, including the functioning of the Quality Management System implemented at university level.

In this context, the higher education institution of physical education and sport in Moldova must assume a realizable mission, centered especially on: their training;

- the training of highly trained staff and the continuous updating of 
- the scientific research in the field, as a central pawn in producing the scientific knowledge that must become as competitive and internationalized as possible.

By strategically analyzing it is important that the scientific research in the field to focus on the following key principles:

- the scientific research in the field to produce quality knowledge;

- knowledge / discovery to be presented / transmitted through publications, patents and / or competitive products / technologies / services;

- once knowledge is produced it is important to pass on the assessment of its impact, which is done in a rather complex way, based on two components: the output of the research (expressed in knowledge with relevance to solving the theoretical and / or practical problems) and impact of output (operationalised through educational consequences, consequences for research and practical consequences, by problem solving at different levels).

\section{Conclusions}

We can state that scientific research in the field of physical education and sport has the role of forming in a critical attitude in the reception of scientific results, and the quality of the research culture has been designed at a university level, treated and evaluated so that it has to promote the productivity of research among the teaching staff, scientific researchers and students. Research culture as part of the research - development-innovation system is perceived in SUPES as a basic pawn in achieving the competitive advantage in the competitive market and of generating economic benefits at national level. Thus, the sustainability of the research culture is assured in the University in the field by developing a dynamic climate oriented to quality scientific research, developed in partnership with other large university centers.

\section{References}

[1] Budevici Puiu L., Budevici Puiu A., The role of the ISO 9001:2008 standard and of the PDCS diagram in the management system of the academic institution in the field. In: The Scientific Theoretical Journal "The Science of Physical Culture", Chisinau, SUPES, 2014, No.1.

[2] Duca G, Petrescu I. The academic management. Central Scientific Publisher, Chisinau, 2015. 
Liliana BUDEVICI-PUIU et al. | Lumen Proceedings 9 | RSACVP2019

[3] Manolachi V, Budevici Puiu L. The Insurance and Evaluation of the Scientific Research Quality within the Institution of Higher Education of Physical Training and Sport from Republic of Moldova. Journal of Management Systems, QUAL ITY 65 Access to success. 2016;17(150).

[4] Manolachi V. The Management and sustainable sport development. Chisinau: SUPES Publisher; 2016. 